\title{
Selection of chemical phosphorus removal scheme based on Analytic Hierarchy Process
}

\author{
Ze Wang ${ }^{1 *}$ \\ ${ }^{1}$ College of Chemistry and Molecular Sciences, Wuhan University, Wuhan, Hubei, 430072, China
}

\begin{abstract}
Chemical precipitation phosphorus removal process can improve the phosphorus removal effect of sewage treatment system to meet the increasingly stringent discharge standards. In order to assist designers in selecting reasonable chemical phosphorus removal schemes, the analytic hierarchy process was applied to quantitatively evaluate each chemical phosphorus removal scheme from four aspects: water treatment effect, operation cost, operation and management difficulty and environmental impact. Finally, combined with an engineering example, the process of analytic hierarchy process quantitative evaluation of chemical phosphorus removal scheme and the method of selecting the optimal scheme are introduced, which provides a reference for the selection of chemical phosphorus removal scheme in engineering.
\end{abstract}

\section{Introduction}

Lake eutrophication is mostly caused by excessive nitrogen and phosphorus in the water body[1]. Studies have shown that excessive phosphorus content in the water body will have a certain inhibitory effect on the growth of submerged plants, which makes it difficult for submerged vegetation to complete the ecological adjustment of the water body[2]. It ultimately leads to the deterioration of environmental water quality. At present, most urban domestic sewage treatment plants use biological methods to remove nitrogen, phosphorus and organic pollutants in sewage, and some industrial wastewater with better biodegradability also uses biological methods to remove nitrogen and phosphorus[3]-[4]. Limited by the mechanism of biological phosphorus removal, in the process of industrial wastewater treatment, if a single biological method is used to treat industrial wastewater with high phosphorus concentration, it is often difficult to meet the total phosphorus treatment requirements in the relevant discharge standards.

The dosing of coagulant is a continuous process along with industrial production. The difference in the type, dosage and dosing method of the coagulant not only affects the phosphorus removal effect of the sewage treatment system, but also affects the effluent $\mathrm{pH}$, effluent color and operation cost of the water treatment system. Therefore, it is particularly important to choose an appropriate chemical phosphorus removal scheme. The analytic hierarchy process is a method that can solve complex decision-making problems in the weight distribution of various factors, which can assist relevant people in making decisions. In recent years, it has also been widely used in the field of water treatment. For example, the application in the optimal selection of water treatment technology, the water quality evaluation of the water source area of the middle route of the South-toNorth Water Transfer Project, and the research on the technology of refining wastewater reuse .

Taking the upgrading and transformation of the phosphorus removal function of a wastewater treatment system of an aquatic product processing enterprise in Wuhan as an example, this paper analyzes the main factors that affect the choice of chemical phosphorus removal scheme in the process of wastewater treatment process design, and establishes a chemical phosphorus removal scheme through the application of analytic hierarchy process. It aims to quantify the chemical phosphorus removal schemes after comprehensively considering the water treatment effect, water treatment cost, management operation difficulty, and environmental impact, and select the best scheme to assist designers in making decisions. It provides a reference for the selection of phosphorus removal schemes in the process of sewage treatment technology design.

\section{Materials and methods}

\subsection{Test water}

The water used for the test in this article was taken from an aquatic product processing plant in Wuhan. The water quality indicators are shown in Table 1.

\subsection{Analytical method}

The total phosphorus in the water is determined by the ammonium molybdate spectrophotometric method; The total nitrogen in the water is determined by the alkaline 
potassium persulfate digestion UV spectrophotometry; The $\mathrm{pH}$ is determined by the $\mathrm{HACH} \mathrm{pHC} 101$ portable detection; The chromaticity is measured by the dilution multiple method.

Table 1. Test water quality

\begin{tabular}{lcccccc}
\hline Project & $\mathrm{COD} /\left(\mathrm{mg} \cdot \mathrm{L}^{-1}\right)$ & $\mathrm{TP} /\left(\mathrm{mg} \cdot \mathrm{L}^{-1}\right)$ & $\mathrm{TN} /\left(\mathrm{mg} \cdot \mathrm{L}^{-1}\right)$ & $\mathrm{NH}_{3}-\mathrm{N} /\left(\mathrm{mg} \cdot \mathrm{L}^{-1}\right)$ & $\mathrm{SS} /\left(\mathrm{mg} \cdot \mathrm{L}^{-1}\right)$ & $\mathrm{PH}$ \\
\hline Influent water quality & $230 \sim 350$ & $60 \sim 70$ & $85 \sim 90$ & $60 \sim 75$ & $120 \sim 150$ & $7.3 \sim 7.8$ \\
Effluent water quality & $60 \sim 70$ & $60 \sim 70$ & $10 \sim 25$ & $5 \sim 18$ & $8 \sim 12$ & $7.2 \sim 7.7$ \\
\hline
\end{tabular}

\section{Evaluation and selection of chemical phosphorus removal scheme}

The test water used in this paper is wastewater produced by a water processing plant in Wuhan. The total phosphorus content in the wastewater is about $60-70 \mathrm{mg}$ $\mathrm{L}^{-1}$, which is much higher than that of urban domestic sewage, and the amount of wastewater discharged is large. The biological method is used to remove phosphorus in the water body. The use of biological methods to remove phosphorus is difficult to meet the discharge requirements, so it is necessary to add a chemical phosphorus removal unit to further remove phosphorus from the water body, and improve the sewage treatment process to remove the total phosphorus effect of the system.

According to the dosage position of drugs, the chemical precipitation phosphorus removal process is generally divided into the front phosphorus removal process, the simultaneous phosphorus removal process and the post phosphorus removal process. The front phosphorus removal process is to add drugs before the sewage enters the biological treatment section. It can not only remove the phosphorus in the water, but also reduce the organic load in the subsequent biological treatment section, but it will increase the system's sludge production and the sludge composition is more complex. The simultaneous phosphorus removal process is to add coagulant at the inlet of the secondary sedimentation tank. Its advantage is that the amount of facilities is relatively

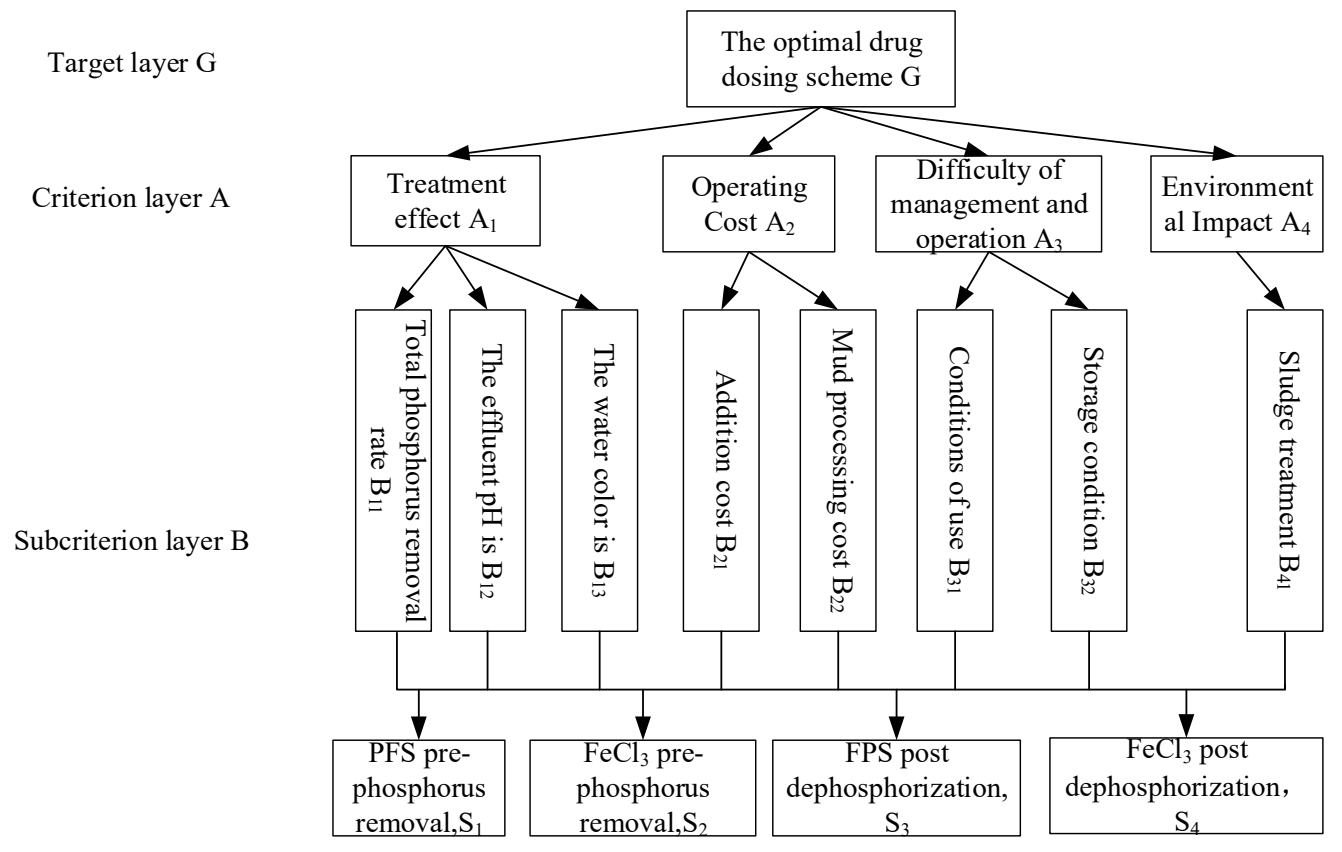

Figure 1. Phosphorus removal program selection hierarchy. small. The post phosphorus removal process separates the chemical precipitation dephosphorization unit from the biological treatment unit so that they do not affect each other, and the produced phosphate sludge can be discharged and collected separately and can be used.

According to the actual situation, the following 4 chemical dephosphorization schemes are designed: predephosphorization and dosing of polymeric ferric sulfate $\left(\mathrm{S}_{1}\right)$, pre-dephosphorization and dosing of ferric chloride $\left(\mathrm{S}_{2}\right)$, post dephosphorization and dosing of polymeric ferric sulfate $\left(\mathrm{S}_{3}\right)$, and post dephosphorization and dosing ferric chlorine $\left(\mathrm{S}_{4}\right)$. The total phosphorus removal rate, effluent $\mathrm{pH}$, effluent color, and dosage of drugs in each scheme were tested. The fuzzy analytic hierarchy process should be used to quantitatively evaluate and select each phosphorus removal scheme.

\subsection{Establishment of the evaluation system of 3.1. Establishment of the evaluation system of
the chemical phosphorus removal program}

\subsubsection{Establishment of hierarchical structure model. The hierarchical structure model generally includes the target layer, the criterion layer and the sub-criteria layer. The key to the analytic hierarchy process is to establish an appropriate hierarchical model based on actual problems and their influencing factors. The hierarchical structure of the chemical phosphorus removal program evaluation system established in this paper is shown in Figure1.}


The decision-making objective in the hierarchical structure shown in Figure 1 is the optimal drug administration scheme G. By fully considering the actual needs of the project, reviewing relevant emission standards and relevant environmental protection regulations, etc.it is determined that the criterion layer $\mathrm{A}$ includes treatment effect $A_{1}$, direct economic cost $A_{2}$, difficulty of management and operation difficulty $A_{3}$, and environmental impact $\mathrm{A}_{4}$. In the criterion layer $\mathrm{A}$, the subcriterion layer $\mathrm{B}$ is set up as a supplement, and the subitems in the criterion layer $\mathrm{A}$ are further divided

Analyze the main purpose of the medicine dosing plan in the target layer, setting the total phosphorus removal rate $B_{11}$, the effluent $\mathrm{pH}$ value $\mathrm{B}_{12}$ and the effluent color $\mathrm{B}_{13}$ as the sub-items of the treatment effect $A_{1}$; Considering the cost of operating the sewage treatment system in the actual project, set up the drugs dosing cost $\mathrm{B}_{21}$ and the mud production treatment cost $\mathrm{B}_{22}$ as subitems of the direct economic cost $\mathrm{A}_{2}$; In addition to considering the treatment effect and operating costs, it is also necessary to fully consider the difficulty of operation and maintenance of the sewage treatment process.
Therefore, the use conditions of the agent $\mathrm{B}_{31}$ and the agent storage requirement $B_{32}$ are set as supplementary sub-items of the management and operation difficulty $A_{3}$; The environmental impact $\mathrm{A}_{4}$ mainly considers the impact of the difference in sludge composition between the front and post dephosphorization schemes on the subsequent sludge treatment, and the $\mathrm{B}_{41}$ sub-item of sludge production treatment is set up.

3.1.2. Judgment matrix construction. The judgment matrix indicates the importance of the comparison between the two indicators in the same criterion layer (or sub-criteria layer) in the hierarchy structure. In this paper, the judgment matrix adopts the 1-9 scale method, and the application description of the scale is shown in Table 2 . In this article, by reviewing relevant literature, comparing the accumulated experimental data from previous periods, and asking experts for their opinions, we have established a judgment matrix corresponding to each criterion layer. The main criterion layer judgment matrix is shown in Table 3 and Table 4.

Table 2. The 1 - 9 scale law judge matrix constructed

\begin{tabular}{ccc}
\hline Scale & Definition & Meaning \\
\hline 1 & Equally important & Tlightly important \\
obviously important & Strongly important & The influence of $i$ is slightly stronger than $j$ \\
7 & absolutely important & The influence of $i$ is stronger than $j$. \\
9 & The influence of $i$ is more obvious than $j$. \\
$2 、 4 、 6 、 8$ & The influence of ci is more absolute than cj. \\
$W_{j i}=1 / W_{i j}$. & If the ratio of factor $i$ to factor $j$ is $W_{i j}$, then the ratio of factor j to factor $i$ is $W_{j i}=1 /$ \\
\end{tabular}

Table 3. G-A judgment matrix

\begin{tabular}{ccccc}
\hline $\mathrm{G}$ & $\mathrm{A}_{1}$ & $\mathrm{~A}_{2}$ & $\mathrm{~A}_{3}$ & $\mathrm{~A}_{4}$ \\
\hline $\mathrm{A}_{1}$ & 1 & 5 & 6 & 5 \\
$\mathrm{~A}_{2}$ & $1 / 5$ & 1 & 3 & 2 \\
$\mathrm{~A}_{3}$ & $1 / 6$ & $1 / 3$ & 1 & 1 \\
$\mathrm{~A}_{4}$ & $1 / 5$ & $1 / 2$ & 1 & 1 \\
\hline
\end{tabular}

Table 4. A1-B judgment matrix

\begin{tabular}{cccc}
\hline $\mathrm{A}_{1}$ & $\mathrm{BA}_{11}$ & $\mathrm{BA}_{12}$ & $\mathrm{BA}_{13}$ \\
\hline $\mathrm{BA}_{11}$ & 1 & 7 & 8 \\
$\mathrm{BA}_{12}$ & $1 / 7$ & 1 & 3 \\
$\mathrm{BA}_{13}$ & $1 / 8$ & $1 / 3$ & 1 \\
\hline
\end{tabular}

3.1.3. Consistency check and weight calculation. The consistency test result of the judgment matrix is generally measured by the consistency ratio $\mathrm{CR}$ :

$$
C R=\frac{C I}{R I}
$$

$C I$ : Quantitative index for judging the consistency of the matrix, $C I=\frac{\lambda \max -n}{n-1}, \lambda_{\max }$ is the characteristic value of the judgment matrix, $\mathrm{n}$ is the order of the judgment matrix;

$R I$ : The value of the average random consistency corresponds to the order $\mathrm{n}$ of the constructed judgment matrix (the value is shown in Table 5).

When $C R<0.1$, the constructed judgment matrix is consistent, otherwise, the judgment matrix constructed above should be adjusted to pass the consistency check. 
Table 5. The average random consistency $R I$

\begin{tabular}{cccccccccc}
\hline Order(n) & 1 & 2 & 3 & 4 & 5 & 6 & 7 & 8 & 9 \\
$R I$ & 0 & 0 & 0.58 & 0.90 & 1.12 & 1.24 & 1.32 & 1.41 & 1.49 \\
\hline
\end{tabular}

The calculation results of the judgment matrix are coefficient are shown in Table 7. shown in Table 6, and the calculation results of the weight

Table 6. Test results of judgment matrix

\begin{tabular}{ccccc}
\hline Project & $\lambda_{\max }$ & $C I$ & $C R$ & Consistence check \\
\hline $\mathrm{G}-\mathrm{A}$ & 4.096 & 0.0320 & 0.0356 & Pass \\
$\mathrm{A}_{1}-\mathrm{B}$ & 3.104 & 0.0522 & 0.0900 & Pass \\
$\mathrm{A}_{2}-\mathrm{B}$ & 2.000 & 0.0000 & 0.0000 & Pass \\
$\mathrm{A}_{3}-\mathrm{B}$ & 2.000 & 0.0000 & 0.0000 & Pass \\
\hline
\end{tabular}

Table 7. Calculation results of weight coefficient

\begin{tabular}{|c|c|c|c|c|}
\hline Target layer $\mathrm{G}$ & Ruler layer A & Weight coefficient & Sub-target layer B & Weight coefficient \\
\hline \multirow{8}{*}{$\begin{array}{l}\text { Optimal drug dosing } \\
\text { schemeG }_{1}\end{array}$} & \multirow{3}{*}{ Treatment effect $\mathrm{A}_{1}$} & \multirow{3}{*}{0.6282} & $\mathrm{~B}_{11}-\mathrm{A}_{1}$ & 0.7766 \\
\hline & & & $\mathrm{B}_{12}-\mathrm{A}_{1}$ & 0.1530 \\
\hline & & & $\mathrm{B}_{13}-\mathrm{A}_{1}$ & 0.0704 \\
\hline & \multirow{2}{*}{ Direct economic $\operatorname{cost} \mathrm{A}_{2}$} & \multirow{2}{*}{0.1874} & $\mathrm{~B}_{21}-\mathrm{A}_{2}$ & 0.8333 \\
\hline & & & $\mathrm{B}_{22}-\mathrm{A}_{2}$ & 0.1667 \\
\hline & \multirow{3}{*}{$\begin{array}{c}\text { Difficulty of management and } \\
\text { opration } \mathrm{A}_{3} \\
\text { Environmental impact } \mathrm{A}_{4}\end{array}$} & \multirow{2}{*}{0.0858} & $\mathrm{~B}_{31}-\mathrm{A}_{3}$ & 0.7500 \\
\hline & & & $\mathrm{B}_{32}-\mathrm{A}_{3}$ & 0.2500 \\
\hline & & 0.0986 & $\mathrm{~B}_{41}-\mathrm{A}_{4}$ & 1.0000 \\
\hline
\end{tabular}

\subsection{Selection of chemical phosphorus removal scheme}

In this article, the water quality indicators in the subcriterion layer B have been tested. Due to the different properties of total phosphorus removal rate, effluent $\mathrm{pH}$ and other indicators, each sub-item indicator has a different dimension and magnitude. If the original data is not pre-processed and used directly, it will often highlight the role of indicators with higher values in the evaluation system and weaken the role of indicators with smaller values. As a result, the weight coefficient calculated by the layered analysis method mentioned above is invalid in the weighting function of the evaluation system.

In order to avoid the unfavorable influence of the difference in the magnitude of the original index value on the evaluation result, this article first standardizes the original data according to the following formula to $0 \sim 1$.

$$
x *=\frac{x-x \min }{x \max -x \min }
$$

$x *$ : The data after standardization is used for the next step of data analysis; $x_{\max }$ : The maximum value of an index in a certain index;

$x$ min: The minimum value of an index in a certain index.

The quantitative results of each scheme are shown in Figure 2.

After standardizing the test data, combined with the weight coefficient mentioned above, each process scheme is scored quantitatively. From the comprehensive score results in Figure 2, it can be seen that the process of each chemical dephosphorization scheme is $\mathrm{S}_{4}>\mathrm{S}_{2}>\mathrm{S}_{1}>\mathrm{S}_{3}$.

$\mathrm{S}_{4}$ has the highest score in the evaluation system, and is considered to be the best technological scheme. It has a better performance in terms of water treatment effect $\left(\mathrm{A}_{1}\right)$ and environmental impact $\left(\mathrm{A}_{4}\right)$, and it also meets the selected technological scheme; However, it should be noted that $\mathrm{S}_{4}$ has a low score in terms of operating cost $\left(\mathrm{A}_{2}\right)$ due to the high cost of $\mathrm{FeCl}_{3}$ addition. In the evaluation system constructed in this paper, the weight of $A_{1}$ is 0.63 , and the weight of $\mathrm{A}_{2}$ is 0.19 , Comprehensively consider to determine $\mathrm{S}_{4}$ is the optimal chemical phosphorus removal program. 


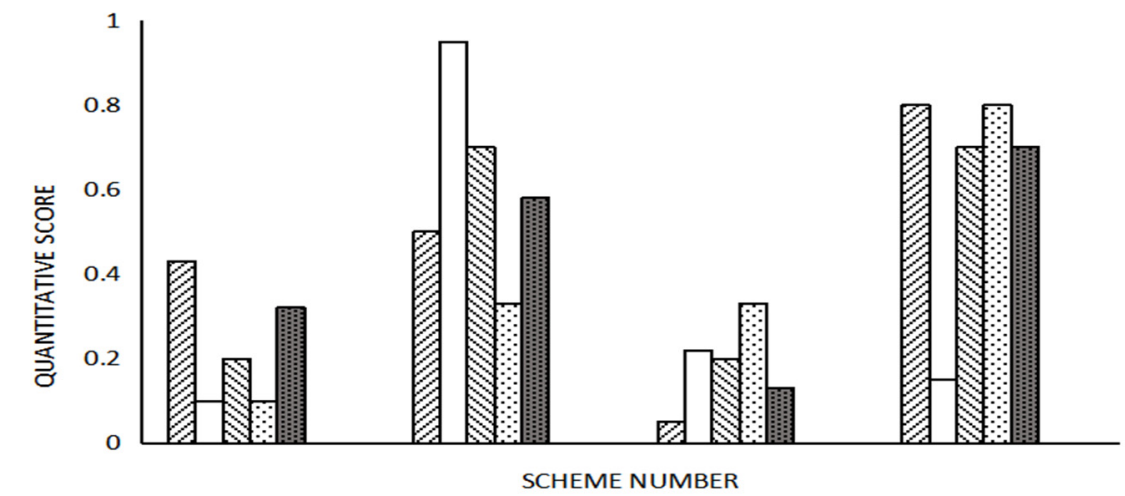

Figure 2 Quantitative results of dephosphorization

\section{scheme}

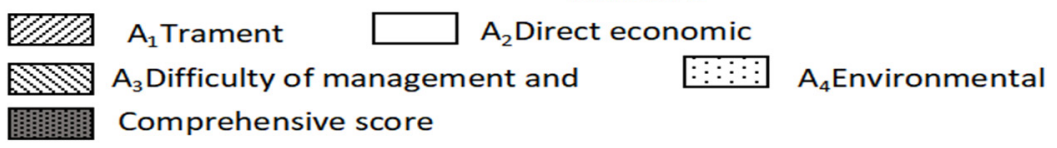

\section{Conclusion}

- The fuzzy analytic hierarchy process is used to construct an evaluation system for chemical phosphorus removal scheme, and the weight coefficients of each factor in the evaluation system are calculated as $A_{1}$ with a weight of 0.63 , $A_{2}$ with a weight of 0.19 , and $A_{3}$ with a weight of $0.09, \mathrm{~A}_{4}$ has a weight of 0.10 , which quantifies the influence of various factors on the choice of chemical phosphorus removal programs.

- The 1-9 scale method is used to construct a dynamic adjustment matrix to meet the criterionlayer judgment matrix required by different engineering design requirements.

- According to the actual situation, 4 kinds of chemical phosphorus removal schemes are designed: pre-dephosphorization and dosing of polymeric ferric sulfate $\left(\mathrm{S}_{1}\right)$, predephosphorization and dosing of ferric chloride $\left(\mathrm{S}_{2}\right)$, post dephosphorization and dosing of polymeric ferric sulfate(S3), and post dephosphorization and dosing of ferric chloride (S4). Applying the fuzzy analytic hierarchy process, the engineering applicability of each scheme is $\mathrm{S}_{4}>\mathrm{S}_{2}>\mathrm{S}_{1}>\mathrm{S}_{3}$, and it is comprehensively determined that $\mathrm{S}_{4}$ is the optimal chemical phosphorus removal scheme.

\section{References}

1. Sun, W., Ma, G., Sun, Y., Liu, Y., Song, N., Xu, Y., \& Zheng, H. (2017). Effective treatment of high phosphorus pharmaceutical wastewater by chemical precipitation. The Canadian Journal of Chemical Engineering, 95(8): 1585-1593.

2. Suzin, L., Antes, F. G., Bedendo, G. C., Bortoli, M., \& Kunz, A. (2018). Chemical removal of phosphorus from swine effluent: The impact of previous effluent

treatment technologies on process efficiency. Water, Air, \& Soil Pollution, 229(11): 1-9.

3. Ojo, P., \& Ifelebuegu, A. O. (2018). The impact of aluminium salt dosing for chemical phosphorus removal on the settleability of activated sludge. Environments, 5(8): 88.

4. Hutnik, N., Stanclik, A., Piotrowski, K., \& Matynia, A. (2019). Recovery of phosphates (V) from wastewaters of different chemical composition. Open Chemistry, 17(1): 1071-1079. 